\title{
Development of a cutting force prediction model based on brittle fracture for carbon fiber reinforced polymers for rotary ultrasonic drilling
}

\author{
Songmei Yuan ${ }^{1} \cdot$ Chong Zhang $^{1} \cdot$ Muhammad Amin $^{1} \cdot$ Huitao Fan ${ }^{1} \cdot$ Ming Liu $^{1}$
}

Received: 18 January 2015 / Accepted: 4 May 2015 / Published online: 20 May 2015

(C) Springer-Verlag London 2015

\begin{abstract}
Carbon fiber reinforced polymers (CFRP) T700 have got increasing demand in the aerospace industry due to their high specific strength, specific stiffness, and other unique properties. Due to their inhomogeneous, anisotropic, and thermal properties, it is challenging to achieve desired accuracy and to avoid from delamination, chip-off, cracking, and burning especially in the drilling process. The cutting force is the critical parameter which is required to minimize in order to drill a hole with better accuracy and minimize defects. In this research, the brittle fracture approach was adopted and a cutting force model was developed for CFRP-T700 based on the rotary ultrasonic drilling (RUD) process. The experimental RUD was carried out on CFRP-T700 material and found that the feed rate and spindle speed are two main parameters that affect the cutting force in RUD. The cutting force data obtained from the model and experimental setup were then analyzed and found that there is small variation even below $10 \%$ (max value of variation is $8.5 \%$ and the average value is $0.49 \%$ ) between simulated and measured values. So, the developed cutting force model was validated and found robust. Also, it was found that with four times increase of feed rate, there is also an increase of material removal rate (MRR) four times with the decrease in the cutting force. Moreover, this model will be much helpful to keep cutting force within limits through the optimal set of parameters as feed rate and spindle
\end{abstract}

Songmei Yuan

yuansm@buaa.edu.cn

School of Mechanical Engineering and Automation, Beijing Engineering Technological Research Center of High-efficient \& Green CNC Machining Process and Equipment, Beihang University, Beijing 100191, China speed without extensive experimentation of such costly materials.

Keywords Carbon fiber reinforced polymers $\cdot$ T700 $~$ Rotary ultrasonic drilling $\cdot$ Cutting force $\cdot$ Brittle fracture $\cdot$ Cutting parameters

\section{Introduction}

Carbon fiber reinforced polymer (CFRP) materials have got paramount importance and have a wide range of application in aerospace and high-performance supporting equipment. These materials have properties such as high specific strength, high specific stiffness, low weight, high corrosion resistance, and low thermal expansion which have made these attractive for aerospace and other weight-sensitive applications. Even though CFRP (also other composites) are often made a nearnet shape, some machining processes are unavoidable. In current aircraft manufacturing, drilling is one the critical machining process to make accurate holes for assembly and rivet pieces together. Unlike metals, composites are inhomogeneous and their interaction with the cutting tool during machining is a complex phenomenon that is required to be investigated. Moreover, CFRP-T700 is inhomogeneous and an anisotropic composite material. Drilling may adversely affect the quality of the composite part because of the rise of defects during this process such as delamination, cracking, fiber pull-out, and burning. These defects, high processing cost, and low processing efficiency are three main problems which hindered the applications of such materials.

Rotary ultrasonic machining (RUM), as one of the special processing methods, has achieved good results compared to conventional machining [1-5]. A theoretical material removal model in drilling advanced ceramics was established based on 
brittle fracture mode [6]. This model discussed the relationship between cutting parameters and material removal rate (MRR) but not predicted the drilling force model [7]. Pei et al. [8] used rotary ultrasonic face machining first time and found the influence of the cutting depth, feed rate, and cutting tool on the machined surface quality and MRR. Zhang et al. [9] established the material removal model based on the indentation theory for advanced ceramic and obtained the theoretical expression of MRR. This research verified the influence of static pressure, amplitude, spindle speed, and the grit size on MRR through experiments. Hu et al. [10] investigated the experimental influence of the drilling parameters on MRR. $\mathrm{Li}$ et al [11] studied rotary ultrasonic drilling on ceramic matrix composites and found that RUM has lower cutting force, better MRR and holes-quality compared to the conventional drilling. This research also showed that feed rate has significant effects on cutting force. Feng et al. [12] established the theoretical model for the rotary ultrasonic face milling with the assumption that the diamond grit was spherical while the shape of the grit found was regular octahedron. Wang et al. [13] conducted a study of rotary ultrasonic drilling on potassium dihydrogen phosphate (KDP) crystal and analyzed the effects of five different cutting parameters on the surface quality. The experiments were carried out; however, the model of the surface roughness was not established. Zhang et al. [14] established a theoretical model to predict the cutting force of rotary ultrasonic drilling engineering for ceramics. Liu et al. [15] developed a rotary ultrasonic drilling force model based on the brittle fracture theory. The shape of the diamond grit was assumed octahedron. Bertsche et al. [16] established an analytical model for rotary ultrasonic milling. Yuan et al. [17] investigated a cutting force model based on ductile-mode for $\mathrm{C} / \mathrm{SiC}$ composites. The cutting depth and the feed rate were considered to be the parameters affecting the cutting force.

In previous study and literature review [1-17], it is found that there was main focus on machining ceramics and its related composite materials. The research work on rotary ultrasonic drilling of CFRP materials is rare especially on CFRPT700. There is a dire need to develop a cutting force model and to find the relationship between cutting force and its significant parameters and cutting force. The effects cutting force have adverse effects on properties of CFRP so there is a need to find optimal relations between cutting force and significant parameters to it.

In this paper, the mechanistic model is developed to predict the cutting force in rotary ultrasonic drilling (RUD) of CFRP materials based on indentation fracture mechanics. The parameter " $\mathrm{K}$ " was obtained using single factor test. This model is then validated with experimental rotary ultrasonic drilling on CFRP. The relationship between cutting force and its significant cutting parameters such as spindle speed and feed rate will be analyzed and discussed. This paper was organized as follows. In section 2, development of cutting force model is described. In section 3, experimental RUD was carried out and data acquired was described. The results and discussion are mentioned in section 3.3. Finally, conclusions are presented in section 4 .

\section{Development of cutting force model}

The development of cutting force model for CFRP by applying RUD and brittle fracture has the following steps in sequence.

\subsection{Establishment of the model}

The material removal mechanism of RUD is based on the indentation fracture theory. When the diamond abrasive grit is penetrated into the face/surface of the part material, there is a plastic deformation. With the increasing penetration depth, median crack will grow and subsequently generates the lateral crack. The extended lateral cracks induced in the material and peeling off of the material from the workpiece/part material was shown in Fig. 1 [16, 17, 19].

The maximum penetration depth was used as an intermediate parameter to establish the relationships between the input parameters like spindle speed, feed rate, and cutting depth with the output parameter as cutting force. There are three assumptions for simplification:

1. The material removal mode is rigid brittle fracture mode. 2. All of the diamond abrasive particles have the same size. 3. The diamond abrasive particles are rigid octahedron.

\subsection{Relationship between maximum penetration depth and cutting force}

In this paper, $w$ is the penetration depth, $\beta$ is the half angle of the diamond abrasive grains, $C_{1}$ is the length of lateral cracks, $C_{\mathrm{h}}$ is the length of median cracks, and $d$ is the penetration width as shown in Fig 1.

From the geometric relationship in Fig. 1, the following formula can be obtained:

$w=\frac{d}{2 \tan \beta}$

According to definition of Vickers-hardness, the following formula can be obtained:

$\mathrm{Hv}=0.102 \times \frac{\mathrm{Fn}}{S}=0.102 \times \frac{2 \mathrm{FnSin} \beta}{d^{2}}$

where Fn is the normal force on the surface of the workpiece, and $\mathrm{Hv}$ is the Vickers-hardness of the workpiece material. 


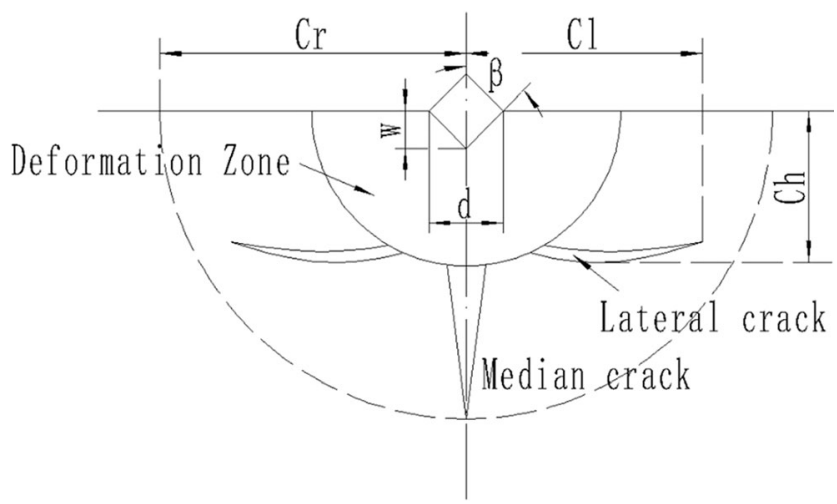

Fig. 1 Crack generation and plastic deformation zone in brittle material [18]

Simultaneously solving Eq. 1 and Eq. 2, the following formula can be obtained:

$w=\sqrt{0.051 \cdot \frac{\cos ^{2} \beta}{\sin \beta} \cdot \frac{\mathrm{Fn}}{\mathrm{Hv}}}$

The volume of a single diamond can be expressed as:

$V=\frac{\sqrt{2}}{3} \mathrm{Sa}^{3}$

where $\mathrm{Sa}$ is the side length of the diamond abrasive grains.

The diamond abrasive concentration is the mass of abrasive per unit volume within the working layer. Concentration is generally defined like per cubic centimeter volume of abrasive grains containing 4.4 karats ( 1 karat diamond is equal to $0.2 \mathrm{~g}$ ) is defined as 100 . With each increase or decrease of 1.1 karats of abrasive, there is $25 \%$ increase or decrease of concentration. According to this definition, the total number of diamond abrasives involved in cutting $(\mathrm{N} \alpha)$ can be expressed as:

$\mathrm{N} \alpha=\left(\frac{0.88 \times 10^{-3}}{(\sqrt{2} / 3) \mathrm{Sa}^{3} \cdot \rho} \cdot \frac{\mathrm{C} \alpha}{100}\right)^{2 / 3} \cdot A_{0}=C_{1} \cdot \frac{C_{\alpha^{\frac{2}{3}}}}{\mathrm{Sa}^{2}} \cdot A_{0}$

where $C_{\alpha}$ is concentration, $\rho$ is the density of the diamond $\left(3.52 \times 10^{-3} \mathrm{~g} / \mathrm{mm}^{3}\right), A_{0}$ is the area of the cutting tool involved in cutting, and $C_{1}$ is a constant number as $C_{1}=3 \times 10^{-2}$.

The relationship of contact area and geometry of the drilling tool is shown in Fig. 2. The $A_{0}$ can be calculated as follows:

$A_{0}=\pi\left(R_{2}^{2}-R_{1}^{2}\right)$

where $R_{2}$ is the external diameter of the drilling tool, $R_{1}$ is the inner diameter.

The relation between $z$ and $f$ can be obtained:

$$
Z=A \sin (2 \pi f t)
$$

where $Z$ is the trajectory of the diamond abrasive grains, $A$ is

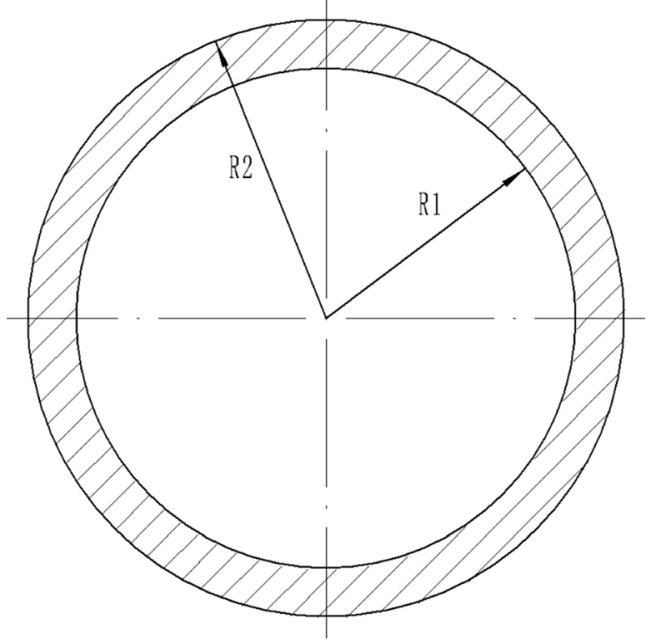

Fig. 2 Contact area $\left(A_{0}\right)$ of the drilling tool

the amplitude, $f$ is the frequency, and $t$ is the time.

According to Eq. 7 , the effective contact time $\Delta t$ can be express as follows:

$\Delta t=\frac{1}{\pi f}\left[\frac{\pi}{2}-\arcsin \left(1-\frac{w}{A}\right)\right]$

Applying the energy conservation theorem, then

$I=\int_{\text {cycle }} F_{\mathrm{m}} \cdot d t \approx F_{\mathrm{m}} \cdot \Delta t$

$I=\frac{F_{\mathrm{r}}}{f}$

where $I$ is impulse, $F_{\mathrm{m}}$ is the maximum impact force, $\Delta t$ is the effective contact time during which an abrasive penetrates into the workpiece, cycle is the vibration cycle of the diamond abrasive grains, and $F_{\mathrm{n}}$ is the cutting force caused by single diamond abrasive.

$F_{\mathrm{n}}=\Delta t \cdot f \cdot F_{\mathrm{m}}$

The cutting force $F$ can be expressed as follows:

$F=N_{\alpha} \cdot F_{\mathrm{n}}$

where $F$ is the cutting force caused by all the active diamond abrasives.

Substituting Eq. 8 and Eq. 12 with Eq. 11:

$F=\frac{N_{\alpha}}{\pi}\left[\frac{\pi}{2}-\arcsin \left(1-\frac{w}{A}\right)\right] \cdot F_{\mathrm{n}}$ 
By solving both Eq. 13 and Eq. 3, the relationship between maximum penetration depth and cutting force can be obtained as follows:

$w=\sqrt{0.051 \cdot \frac{\cos ^{2} \beta}{\sin \beta} \cdot \frac{1}{H_{\mathrm{v}}} \cdot \frac{\pi \cdot F}{N_{\alpha} \cdot\left[\frac{\pi}{2}-\arcsin \left(1-\frac{w}{A}\right)\right]}}$

\subsection{Relationship between maximum penetration depth and cutting parameters}

According to the indentation theory and the research by Marshall and Lawn [19-21], the length of lateral crack $C_{1}$ and the depth of median crack $C_{\mathrm{h}}$ can be expressed as follows:

$$
\begin{aligned}
& C_{1}=C_{2} \cdot\left(\frac{1}{\tan \beta}\right)^{5 / 12} \cdot\left(\frac{E^{3 / 4}}{H_{\mathrm{v}} K_{\mathrm{IC}}\left(1-v^{2}\right)^{1 / 2}}\right)^{1 / 2} \cdot F_{\mathrm{n}}{ }^{5 / 8} \\
& C_{\mathrm{h}}=C_{2} \cdot\left(\frac{1}{\tan \beta}\right)^{1 / 3} \cdot \frac{E^{1 / 2}}{H_{\mathrm{v}}} \cdot F_{\mathrm{n}}{ }^{1 / 2}
\end{aligned}
$$

where $K_{\mathrm{IC}}$ is the fracture toughness of the workpiece material, $E$ is the modulus of elasticity, $C_{2}$ is a constant number, $C_{2}=$ 0.226 , and $\nu$ is the Poisson's ratio.

The penetration depth increases from 0 to $w$ first and then decreases to 0 within $\Delta t$, and the side length at $C_{\mathrm{h}}$ is $2 C_{\mathrm{l}}$. Accordingly, the theoretical material removal volume $V_{0}$ during one penetration period is nearly equal to the volume of the pentahedron [4] and can be expressed as follows.

$L_{\mathrm{s}}=\frac{2 \pi \mathrm{SR}}{60} \cdot \Delta t$

$V_{0}=2 V_{\mathrm{ABCD}}=\frac{1}{3} C_{1} \cdot C_{\mathrm{h}} \cdot L_{\mathrm{s}}$

where $L_{\mathrm{s}}$ is the length when the abrasive particle moves within one period $\Delta t, R$ is the distance from the abrasive particle of the center of the conic tool in $\mathrm{mm}$, and $S$ is the spindle speed in rpm.

Fig. 3 Experimental RUD setup
The material removal volume $(V)$ within one penetration period is nearly equal to the volume of theoretical material removal volume $\left(V_{0}\right)$. It is assumed that $V$ and $V_{0}$ are in linear proportion and found as under:

$V=k V_{0}=\frac{1}{3} k \cdot C_{1} \cdot C_{\mathrm{h}} \cdot \frac{2 \pi \mathrm{SR}}{60} \cdot \Delta t$

where $k$ is a constant and can be obtained from cutting force experiments.

$\mathrm{MRR}_{\mathrm{a}}$ is the material removal rate of single diamond abrasive. Since $V$ is the material removal volume caused by single diamond abrasive in one vibration. Also, $\mathrm{MRR}_{\mathrm{a}}$ can be expressed as follows:

$\mathrm{MRR}_{\mathrm{a}}=f \cdot V=\frac{k}{90} \cdot C_{1} \cdot C_{\mathrm{h}} \cdot S \cdot R \cdot\left[\frac{\pi}{2}-\arcsin \left(1-\frac{w}{A}\right)\right]$

The material removal rate, $\mathrm{MRR}_{\mathrm{T}}$ is the total material removed by all the effective abrasive particles during one period and can be expressed as follows:

$$
\begin{aligned}
\mathrm{MRR} & =N_{\alpha} \cdot \mathrm{MRR}_{\mathrm{a}}=N_{\alpha} \cdot f \cdot V \\
& =\frac{k}{90} \cdot N_{\alpha} \cdot C_{1} \cdot C_{\mathrm{h}} \cdot S \cdot R \cdot\left[\frac{\pi}{2}-\arcsin \left(1-\frac{w}{A}\right)\right]
\end{aligned}
$$

For simplification, average radius $\frac{R_{1}+R_{2}}{2}$ was used instead of $R$ :

$$
\begin{aligned}
\mathrm{MRR} & =N_{\alpha} \cdot \mathrm{MRR}_{\mathrm{a}} \\
& =N_{\alpha} \cdot f \cdot V \approx \frac{k}{90} \cdot N_{\alpha} \cdot C_{1} \cdot C_{\mathrm{h}} \cdot S \cdot \frac{R_{1}+R_{2}}{2} \cdot\left[\frac{\pi}{2}-\arcsin \left(1-\frac{w}{A}\right)\right]
\end{aligned}
$$

$\mathrm{MRR}_{\mathrm{T}}$ can also be expressed as the volume swept by the conic tool during one period:

$\operatorname{MRR}=f_{\mathrm{r}} \cdot A_{0}$

By solving both Eq. 22 and Eq. 23, the relationship between maximum penetration depth and cutting parameters was obtained as follows:

\section{Fig. 3 Experimental RUD setup}

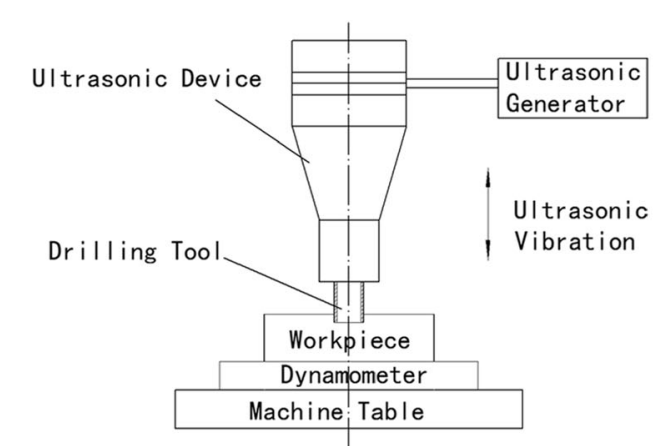

(a)

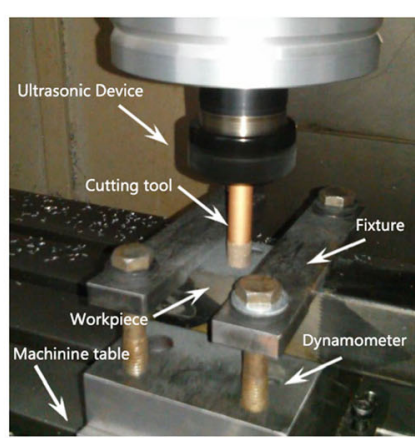

(b) 
Table 1 Properties of the machine tool

\begin{tabular}{lr}
\hline $\begin{array}{l}\text { Spindle speed (with } \\
\text { ultrasonic device) }\end{array}$ & $0-6000 \mathrm{rpm}$ \\
\hline Ultrasonic amplitude & $15 \mu \mathrm{m}$ \\
Ultrasonic frequency & $22,500 \mathrm{~Hz}$ \\
\hline
\end{tabular}

Table 2 The mechanical properties of $\mathrm{T} 700$ composite

\begin{tabular}{ll}
\hline Density $(\rho)$ & $1.8 \mathrm{~g} / \mathrm{cm}^{3}$ \\
\hline $\begin{array}{l}\text { Poisson's ratio }(\nu) \\
\text { Elastic modulus }(E)\end{array}$ & 0.30 \\
$\begin{array}{l}\text { Fracture toughness } \\
\left(K_{\mathrm{IC}}\right)\end{array}$ & $11.5 \mathrm{GPa}$ \\
$\begin{array}{l}\text { Vickers-hardness }\left(H_{\mathrm{v}}\right) \\
\text { M }\end{array}$ & 0.6 \\
\hline
\end{tabular}

$K \cdot C_{3} \cdot S \cdot \tan ^{-3 / 4} \beta \cdot\left[\frac{E^{7 / 4}}{H \mathrm{v}^{3} \cdot K_{\mathrm{IC}} \cdot\left(1-v^{2}\right)^{1 / 2}}\right]^{1 / 2} \cdot F^{9 / 8} \cdot\left(R_{1}+R_{2}\right) \cdot \frac{C_{\alpha}^{2 / 3}}{\mathrm{Sa}^{2}} \cdot\left[\frac{\pi}{2}-\arcsin \left(1-\frac{w}{A}\right)\right]=f_{\mathrm{r}}$

$C_{3}$ is a constant number, $C_{3}=\left(\frac{C_{1} \cdot C_{2}{ }^{2}}{90 \times 2}\right)=8.51 \times 10^{-6}$

\subsection{Cutting force model}

By solving both Eq. 14 and Eq. 24, the relationship between cutting force and cutting parameters was established.

For further simplification, the contact time $\Delta t$ can be found as:

$$
\Delta t=\frac{w}{\pi \mathrm{Af}}
$$

Hence, the relationship between cutting force $F$ and cutting parameters was expressed as:

$F=K^{\prime} \cdot\left[\frac{f_{\mathrm{r}}^{24} \cdot \tan ^{26} \beta \cdot H_{\mathrm{v}}{ }^{44} \cdot K_{\mathrm{IC}}{ }^{12}\left(1-\nu^{2}\right)^{6} \cdot S_{\mathrm{a}}{ }^{32} \cdot A^{16} \cdot A_{0}{ }^{8}}{C_{4}{ }^{24} \cdot S^{24} \cdot \cos ^{8} \beta \cdot E^{21} \cdot\left(R_{1}+R_{2}\right)^{24} \cdot \mathrm{C}_{\alpha}{ }^{\frac{32}{3}}}\right]^{\frac{1}{35}}$

where:

$$
C_{4}=C_{3} \cdot\left(\frac{0.051 \cdot \pi}{C_{1}}\right)^{\frac{1}{3}}=1.49 \times 10^{-5}
$$

This is the developed cutting force model with cutting parameters as spindle speed and feed rate as variables. This

Table 3 Properties of the diamond tool model was then validated through RUD experiments on CFRP-T700 materials in the coming sections.

\section{Experimental verification}

This section provides the specific details on experiment setup, procedure and design of parameters, which were applied for RUD of CFRP-T700.

\subsection{Experimental setup and conditions}

The experimental setup was schematically illustrated in Fig. 3a, and the actual setup was shown in Fig. 3b. The experiments were performed on a 3 -axis vertical machining center (VMC 0850B, Shenyang, China) having ultrasonic vibration device (Tianjin University, China). The ultrasonic vibration device/system has ultrasonic spindle along with ultrasonic generator. The cutting force was measured by dynamometer (9257B, Kistler, Switzerland). The main specifications of the machine tool related to RUD are depicted in Table 1. The carbon fiber reinforced polymer T700 was used as the workpiece material. The mechanical properties of this material are shown in Table 2. The conical shape diamond abrasive drilling tool was applied for the drilling process. The properties of this tool are reported in Table 3.

There are three types of parameters in the cutting force model like workpiece properties, cutting tool properties, and

\begin{tabular}{ll}
\hline Abrasive & Diamond \\
\hline Bond type & Brazing-bond \\
Grain size & $80 / 100$ \\
Concentration & $C \alpha=100$ \\
Outer diameter & $R_{2}=12$ \\
Inner diameter & $R_{1}=9.8$ \\
\hline
\end{tabular}

Table 4 Experimental design data

\begin{tabular}{lccc}
\hline Factor & Level 1 & Level 2 & Level 3 \\
\hline Spindle speed $(\mathrm{r} / \mathrm{min})$ & 1500 & 3000 & 6000 \\
Feed rate $(\mathrm{mm} / \mathrm{min})$ & 30 & 60 & 120 \\
\hline
\end{tabular}


Fig. 4 Cutting force measurements (feed rate $60 \mathrm{~mm}$ / min, spindle speed $3000 \mathrm{rpm})$

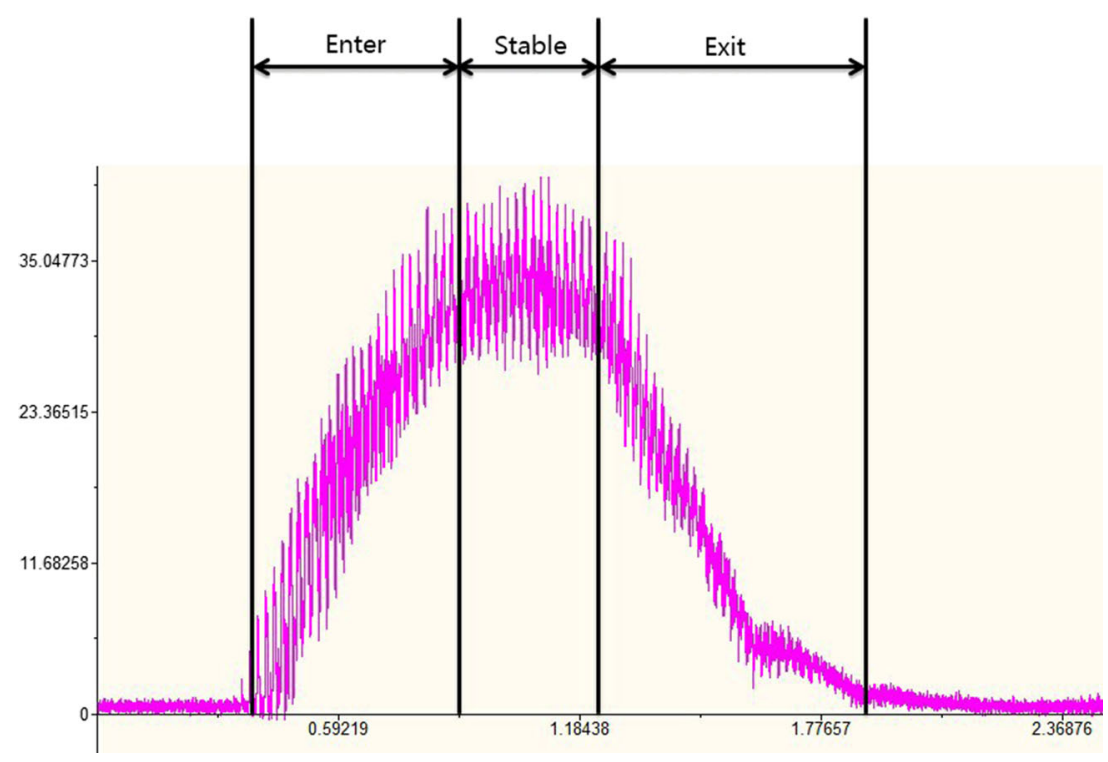

cutting parameters. The first two of these parameters cannot be changed when materials and cutting tool are selected. The spindle speed, feed rate, frequency, and vibration amplitude are four variable input parameters. The frequency is the resonant frequency which does not change in the process. According to the previous theoretical analysis, the material can be removed easily in brittle fracture mode with greater amplitude. When frequency is the resonance frequency, the amplitude attains its maximum value. In this experimentation, the resonance frequency was set as $22,500 \mathrm{~Hz}$ and the maximum amplitude as $15 \mu \mathrm{m}$. So, the spindle speed and feed rate have found two input variables/parameters.

The experimental design data was shown in Table 4. The cutting parameters such as spindle speed and feed rate are designed by single factor experiment array with two factors at three levels. The maximum spindle speed for an ultrasonic device was taken as $6000 \mathrm{rpm}$. Through the theoretical calculation and random experiments, it was found that when the spindle speed is lower than $1500 \mathrm{rpm}$, the cutting force is too large and the rotary ultrasonic drilling process is not feasible under this situation. Therefore, the spindle speed that has been chosen are 1500, 3000, and 6000 three levels. When the spindle speed is $1500 \mathrm{rpm}$ and feed rate is higher than $120 \mathrm{~mm} /$ min, the cutting force was found higher which has an adverse effect on machined surface quality and generally not acceptable. When the feed rate is lower than $30 \mathrm{~mm} / \mathrm{min}$, the material removal rate (MRR) is too low and it is not suitable for the actual processing. So, the three levels of feed rate that have been chosen are 30,60 , and 120 .

\subsection{Obtaining the parameter $K^{\prime}$}

The rotary ultrasonic drilling process was divided into three stages, i.e., Enter, Stable, and Exit as shown in Fig. 4. The drilling force value was the mean value of the stable stage obtained through measurement.

Table 5 Results of cutting force test

\begin{tabular}{|c|c|c|c|c|c|}
\hline $\begin{array}{l}\text { Spindle speed } \\
\mathrm{r} / \mathrm{min}\end{array}$ & $\begin{array}{l}\text { Feedrate } \\
\mathrm{mm} / \mathrm{min} \\
\mathrm{N}\end{array}$ & $\begin{array}{l}\text { Normal force } \\
(F, \text { measure }) \\
\mathrm{N}\end{array}$ & $\begin{array}{l}\text { Normal force } \\
\left(F_{\mathrm{s}}^{\prime}, \text { simulation without } K^{\prime}\right) \\
\mathrm{N}\end{array}$ & $\begin{array}{l}\text { Normal force } \\
\left(F_{\mathrm{s}}, \text { simulation with } K^{\prime}\right)\end{array}$ & Error $\frac{\left(F_{\mathrm{s}}-F\right)}{F} \times 100 \%$ \\
\hline 1500 & 30 & 35.22 & 5.24 & 34.53 & $-1.96 \%$ \\
\hline 1500 & 60 & 54.69 & 8.44 & 55.62 & $1.70 \%$ \\
\hline 1500 & 120 & 87.56 & 13.57 & 89.43 & $2.12 \%$ \\
\hline 3000 & 30 & 24.76 & 3.26 & 21.48 & $-1.32 \%$ \\
\hline 3000 & 60 & 33.33 & 5.24 & 34.53 & $3.60 \%$ \\
\hline 3000 & 120 & 55.16 & 8.44 & 55.62 & $0.83 \%$ \\
\hline 6000 & 30 & 14.31 & 2.03 & 13.38 & $-6.50 \%$ \\
\hline 6000 & 60 & 23.48 & 3.26 & 21.48 & $-8.52 \%$ \\
\hline 6000 & 120 & 32.71 & 5.24 & 34.53 & $5.56 \%$ \\
\hline
\end{tabular}




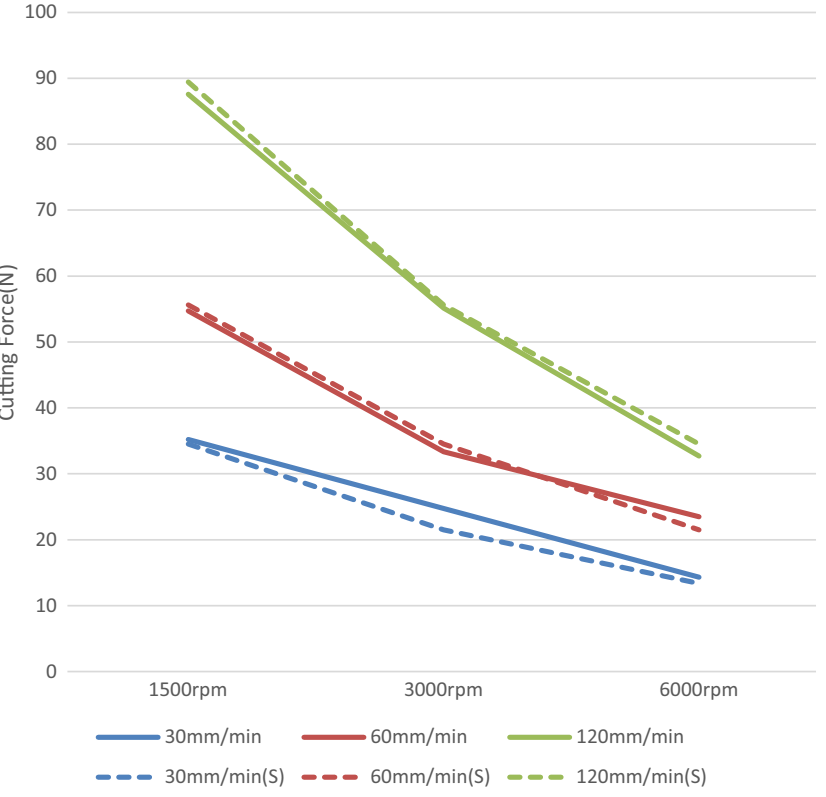

Fig. 5 Comparison of simulation and measurement of cutting force

The cutting force data obtained through experimental RUD on CFRP-T700 was reported in column 3 of Table 5 corresponding to their set of parameters (spindle speed and feed rate). This table has shown the results of the cutting force test. It has found that the simulation values are closest to measurement values, when $\sum\left(F-K^{\prime} \times F_{\mathrm{S}}\right)^{2}$ got the minimum value. $K^{\prime}$ was obtained as 6.52 . The comparison of simulated and measured values of cutting force was shown in Fig. 5.

\subsection{Experimental results and discussion}

The cutting force obtained through experimental RUD and simulation was recorded in Table 5. Then, difference/error in both of these was calculated and found that this difference/ error is lower than $10 \%$ (maximum error is $8.52 \%$ ) as shown in Fig. 5. The average value of this error was found as $0.49 \%$. These results indicate that the cutting force model developed in this research can accurately reflect the actual cutting force which is the major parameter required to be minimized for better quality and machinability. So, the prediction of cutting

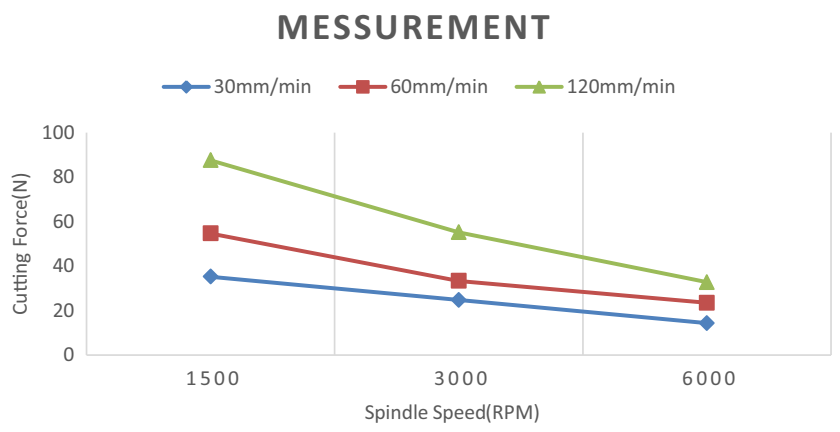

Fig. 6 Relationship between cutting force and spindle speed

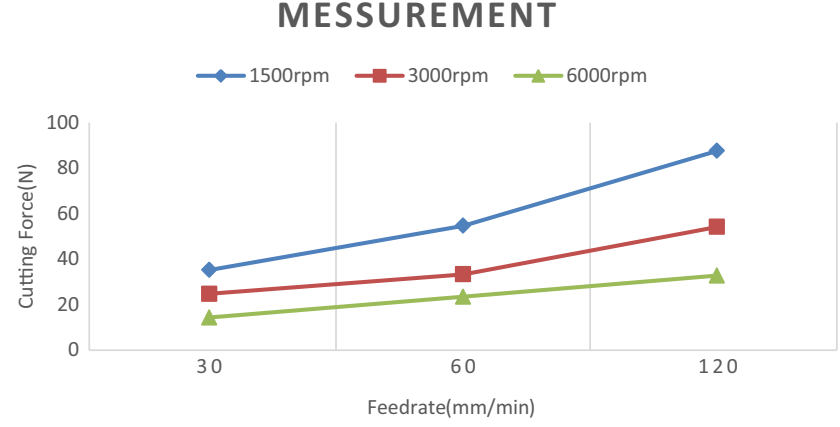

Fig. 7 Relationship between cutting force and feed rate

force will be much helpful for setting of machining parameters with expensive and time-consuming experimentation and to save costly CFRP-T700 materials.

The effects of spindle speed and feed rate on cutting force have analyzed curves and found that the cutting force has decreased with the increase of spindle speed as shown by the graph of Fig. 6. On the other hand, the cutting force has increased with the increase of feed rate as obvious from the graph of Fig. 7.

The graph between spindle speed and feed rate was drawn as shown in Fig. 8. From this graph, a comparison was made and found that cutting $F_{1}$ has numerical value of $35.22 \mathrm{~N}$ with spindle speed of $1500 \mathrm{rpm}$ and feed rate of $30 \mathrm{~mm} / \mathrm{min}$. Also, the cutting force $F_{2}$ has a numerical value of 32.71 with a spindle speed of $6000 \mathrm{rpm}$ and feed rate of $120 \mathrm{~mm} / \mathrm{min}$. From this analysis, it was found that feed rate has increased 4 times (i.e., $120 \mathrm{~mm} / \mathrm{min}$ ) as compared to its initial value (i.e., $30 \mathrm{~mm} / \mathrm{min}$ ) while the cutting force has decreased. Since MRR is directly related to feed rate, so it was found that MRR also increased by 4 times, but the cutting force has decreased at the stage where the cutting force is $32.71 \mathrm{~N}$, spindle speed is $6000 \mathrm{rpm}$, and feed rate is $120 \mathrm{~mm} / \mathrm{min}$. This finding suggests that high spindle speed and feed rate should be adopted to carry on the processing. But it is important to note that this trend only exist in a certain range. The tendency

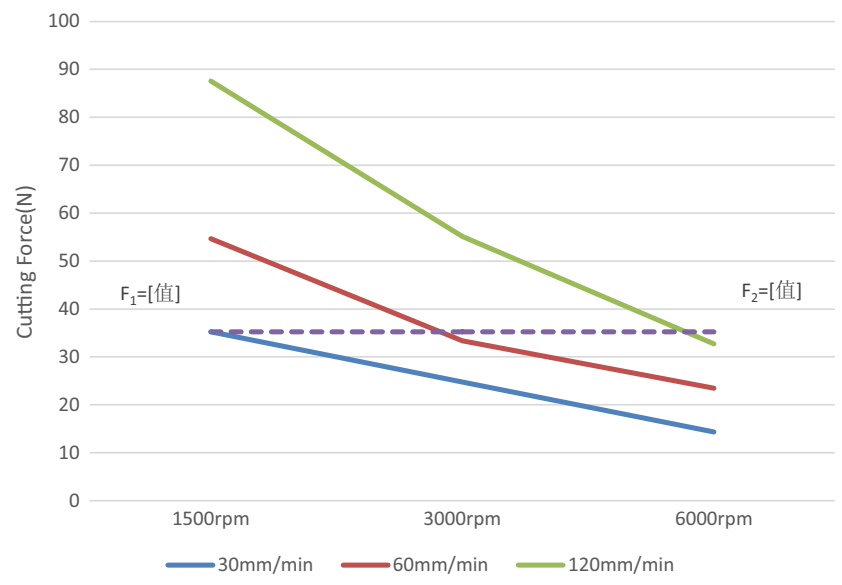

Fig. 8 Comparing of cutting force in different cutting parameters 
Table 6 Correlation analysis

\begin{tabular}{lllll}
\hline Correlations & & & & \\
\hline \multirow{3}{*}{ Spindle speed } & & Spindle speed & Feed rate & Cutting force \\
& Pearson correlation & 1 & 0.000 & -0.664 \\
& Sig. (2-tailed) & & 1.000 & 0.051 \\
Feed rate & $N$ & 9 & 9 & 9 \\
& Pearson correlation & 0.000 & 1 & 0.660 \\
& Sig. (2-tailed) & 1.000 & & 0.053 \\
Cutting force & $N$ & 9 & 9 & 9 \\
& Pearson correlation & -0.664 & 0.660 & 1 \\
& Sig. (2-tailed) & 0.051 & 0.053 & \\
\hline
\end{tabular}

of the cutting force still required research when the spindle speed continues to rise. It needs to improve the highest rotational speed of the ultrasonic device in further research.

The correlation analysis was carried out by SPSS software (statistical software by IBM), and the data obtained was arranged in Table 6. The data was further analyzed and found that the spindle speed and the feed rate are the two main factors/parameters which have the greater influence on cutting force (Pearson correlation are 0.664 and 0.660 ). The Pearson correlation of spindle speed and feed rate was found as 0.00 which predicts that the spindle speed and feed rate are not dependent on each other. So, there is no interaction effect between these two parameters.

\section{Conclusions}

In this research, a cutting force model for RUD of CFRP-T700 composite materials was developed based on the brittle fracture material removal mechanism. The experimental RUD was carried out, and the results were analyzed and discussed. Major conclusions are inferred as follows:

1. The developed cutting force model predicts the cutting force accurately because the error/difference is less than $10 \%$. The average error found is $0.49 \%$ and on the lower side up to $3000 \mathrm{rpm}$ is $3.60 \%$. This value of error then increased at higher spindle speeds of $6000 \mathrm{rpm}$ but less than $10 \%$ again. Practically, much higher spindle speeds are avoided in the drilling process. So, this model is robust and predicts accurately the cutting force in RUD of CFRP-T700 composite material provided spindle speed and feed rate as input variable parameters while the other conditions are same as kept in this research.

2. The drilling/cutting force was found decreased with the increase of spindle speed. On the other hand, the cutting force was found increased with the increase of feed rate as depicted by the graphs of Fig. 6 and Fig. 7 .
3. The cutting force was found as $35.22 \mathrm{~N}$ with the spindle speed of $1500 \mathrm{rpm}$ and feed rate of $30 \mathrm{~mm} / \mathrm{min}$. Also, the cutting force was recorded as $32.71 \mathrm{~N}$ at the spindle speed of $6000 \mathrm{rpm}$ and feed rate of $120 \mathrm{~mm} / \mathrm{min}$. Here, the feed rate has a value of $120 \mathrm{~mm} / \mathrm{min}$ (4 times increase from the initial value of $30 \mathrm{~mm} / \mathrm{min}$ ) which ultimately has increased MRR by 4 times at this stage. This has indicated that higher feed rate and higher spindle speed can be used in RUD of CFRP-T700 composites in order to obtain higher process efficiency (4 times higher) and lower drilling/cutting forces.

The developed model can be used for the prediction of drilling force in RUD of CFRP-T700 composites, and minimum cutting force value can be achieved by selecting the optimal set of values of input parameters as spindle speed and feed rate. This model provides optimization of RUD for CFRP-T700 composites under the conditions applied in this research and can be avoided from expensive, time-consuming, and tedious experimentation especially in case of costly materials. This model contains other parameters also and other related parameters of RUD can be considered for future research work such as semi-angle, grit size, and concentration.

Acknowledgments This research was financially supported by the National High Technology Research and Development Program of China under program No. 863 with Grant no. 2013AA040105 and Basic Scientific Research Program of China. The authors are indebted to this financial support to accomplish this research work.

\section{References}

1. Pei ZJ, Khanna N, Ferreira PM (1995) Rotary ultrasonic machining of structural ceramics-a review[C]//ceram. Eng Sci Proc 16(1):25978

2. Wang X, Zhou M, Gan JGK et al (2002) Theoretical and experimental studies of ultraprecision machining of brittle materials with ultrasonic vibration. Int J Adv Manuf Technol 20(2):99-102

3. Feng Q, Cong WL, Pei ZJ et al (2012) Rotary ultrasonic machining of carbon fiber-reinforced polymer: feasibility study. Mach Sci Technol 16(3):380-398 
4. Zhang C, Cong W, Feng P, Pei Z (2014) Rotary ultrasonic machining of optical K9 glass using compressed air as coolant: a feasibility study. Proc Inst Mech Eng B J Eng Manuf 228(4):504-514

5. Liu JW, Baek DK, Ko TJ (2014) Chipping minimization in drilling ceramic materials with rotary ultrasonic machining. Int $\mathrm{J}$ Adv Manuf Technol 72(9-12):1527-1535

6. Pei ZJ, PRRABHAKAR D, Ferreira PM, Haselkorn M (1995) A mechanistic approach to the prediction of material removal rates in rotary ultrasonic machining. J Eng Ind 117(2):142-151

7. Pei ZJ, Ferreira PM, Kapoor SG, Haselkorn M (1995) Rotary ultrasonic machining for face milling of ceramics. Int J Mach Tool Manuf 35(7):1033-1046

8. Pei ZJ, FerreiraP M (1999) An experimental investigation of rotary ultrasonic face milling. Int J Mach Tool Manuf 39:1327-1344

9. Zhang QH, Wu CL, Sun JL, Jia ZX (2000) The mechanism of material removal in ultrasonic drilling of engineering ceramics. Proc Inst Mech Eng B J Eng Manuf 214(9):805-810

10. Hu P, Zhang JM, Pei ZJ, Treadwell C (2002) Modeling of material removal rate in rotary ultrasonic machining: designed experiments. J Mater Process Technol 129(1):339-344

11. Li ZC, Jiao Y, Deines TW, Pei ZJ, Treadwell C (2005) Rotary ultrasonic machining of ceramic matrix composites: feasibility study and designed experiments. Int J Mach Tool Manuf 45: 1402-1411

12. Feng DJ, Zhao FL, Xu ZG, Guo DM (2006) Mathematic model of material removal rate for ultrasonic milling. China Mech Eng 17(13):1399-1403
13. Wang QG, Cong WL, Pei ZJ, Gao H, Kang RK (2009) Rotary ultrasonic machining of potassium dihydrogen phosphate(KDP) crystal: an experimental investigation on surface roughness. J Manuf Process 11:66-73

14. Zhang CL, Feng PF, Wu ZJ, Yu DW (2011) Mathematical modeling and experimental research for cutting force in rotary ultrasonic drilling. J Mech Eng 47(15):149-155

15. Liu DF, Cong WL, Pei ZJ, Tang YJ (2012) A cutting force model for rotary ultrasonic machining of brittle materials. Int J Mach Tool Manuf 52:77-84

16. Bertsche E, Ehmann K, Malukhin K (2013) An analytical model of rotary ultrasonic milling. Int J Adv Manuf Technol 65(9-12):17051720

17. Yuan S, Zhang C, Hu J (2014) Effects of cutting parameters on ductile material removal mode percentage in rotary ultrasonic face machining. Proc Inst Mech Eng B J Eng Manuf 0954405414548497

18. Liu DF, Cong WL, Pei ZJ et al (2012) A cutting force model for rotary ultrasonic machining of brittle materials. Int J Mach Tools Manuf 52(1):77-84

19. Lawn BR, Evans AG, MarshallD B (1980) Elastic/plastic indentation damage in ceramics: the median/radial crack system. J Am Ceram Soc 63(9-10):574-581

20. Marshall DB, Lawn BR, Evans AG (1982) Elastic/plastic indentation damage in ceramics: the lateral crack system. J Am Ceram Soc 65(11):561-566

21. Collins JA (1981) Failure of materials in mechanical design. Wiley, New York 